\title{
Designing locally-appropriate conservation incentives for small-scale fishers
}

Hollie Booth*1, M Said Ramdlan², Ayesha Hafizh ${ }^{3}$, Karto Wongsopatty ${ }^{3}$, Susana Mourato ${ }^{4}$, Thomas Pienkowski1, Luky Adrinato ${ }^{3}$, EJ Milner-Gulland ${ }^{1}$

1. The Interdisciplinary Centre for Conservation Science, Department of Zoology, University of Oxford, 11a Mansfield Rd, Oxford OX1 3SZ, UK.

2. Universitas Nahdlatul Ulama NTB, Mataram, Indonesia

3. Bogor Agricultural University, Faculty of Fisheries and Marine Sciences, Kampus IPB Dramaga, Jl. Agatis, Bogor 16680 Jawa Barat, Indonesia

4. Department of Geography and Environment and the Grantham Research Institute for Climate change and the Environment, The London School of Economics and Political Science, London, UK

*Corresponding author: hollie.booth@zoo.ox.ac.uk

\section{Abstract}

Large, long-lived marine animals ('marine megafauna') are amongst the world's most threatened taxa, primarily due to overfishing. Reducing fisheries' impacts on marine megafauna is particularly challenging in small-scale fisheries (SSFs), where endangered species can have important consumptive use values. Payments for ecosystem services (PES) have been proposed as a potential solution, but there is a lack of empirical data on if and how they might work in this context. We present a novel combination of methods - scenario interviews with contingent valuation (CV) - for exploring and designing locally-appropriate PES schemes, and apply these methods to investigate how different types of incentives might influence fisher behaviour and mortality of Critically Endangered taxa in two case study SSFs in Indonesia. Fishers almost unanimously supported positive performance-based incentives: $98 \%$ and $96 \%$ of fishers would stop landing hammerhead sharks (Sphyma spp.) and wedgefish (Rhynchobatus spp.), respectively, in contrast to $1 \%$ and $6 \%$ under a business-as-usual scenario, and $52 \%$ and $46 \%$ in response to a negative incentive (fine). CV results showed that an incentive-based scheme for catch mitigation of all hammerheads and wedgefish across both sites could cost US $\$ 71,408$ - 235,927 annually, and save up to 18,500 and 2,140 individuals, respectively. This study provides empirical evidence that PES could offer a cost-effective and socially-just approach for marine conservation in SSFs, and offers a scalable method for 
designing locally-appropriate investment-ready schemes, which could support the delivery of global policy goals such as net positive outcomes for marine biodiversity and a sustainable and equitable blue economy.

Key words: behaviour change, scenarios, contingent valuation, endangered species, payments for ecosystem services, marine megafauna

\section{Introduction}

Large, long-lived marine animals ('marine megafauna') are amongst the world's most threatened taxa (Dulvy et al., 2021; IUCN, 2021). They comprise ancient, diverse and charismatic species, which play critical roles in generating marine ecosystem services and contributions to human well-being - from food and recreation, to maintaining healthy reefs and fisheries (Pimiento et al., 2020; Stein et al., 2018). As such, their loss not only threatens biodiversity itself, but the ability of the ocean to sustain life on earth.

International policy frameworks, such as the Convention on Biological Diversity (CBD), the Sustainable Development Goals (SDGs), the Convention on the International Trade of Endangered Species (CITES) and plans for 'blue growth' outline bold ambitions for conserving biodiversity and ecosystems, whilst enabling humanity to flourish - such as: "living in harmony with nature" by 2050 (CBD), "conserve and sustainably use the oceans... for sustainable development" (SDG 14) and a "sustainable and equitable blue economy" (Bennett et al., 2019). Since marine megafauna are primarily threatened by overfishing, including both targeted and incidental catches (Lewison et al., 2004), delivering these ambitions requires changing the behaviour of fishers and fishing firms. Technologies and practices that reduce fisheries impacts on marine megafauna are well documented (e.g. BMIS, 2021), but less is known about how to encourage their adoption. Encouraging uptake is challenging because it necessitates changing human behaviour amidst trade-offs between biodiversity conservation and the important socio-economic value of fisheries (Booth, Arlidge, et al., 2021; Campbell \& Cornwell, 2008).

50 Trade-offs between marine biodiversity conservation and fisheries objectives can be particularly severe in small-

51 scale mixed-species fisheries, where almost all catches have economic or subsistence value. Such fisheries are ubiquitous throughout coastal waters, especially in biodiversity-rich low-latitude developing nations, which are 
often highly dependent on marine resources (Golden et al., 2016; Selig et al., 2018). In these contexts, traditional command and control approaches to marine conservation - such as regulations and sanctions - may leave coastal communities facing an inequitable burden of the costs of conservation, with negative impacts on the well-being of some of the world's most vulnerable people (Booth, Squires, et al., 2021; Jaiteh et al., 2017; Stevenson et al., 2013). marine biodiversity whilst ensuring coastal communities are no worse off (Bladon et al., 2016).

PES can be defined as a voluntary transaction between an ecosystem service (ES) buyer and an ES provider in which a well-defined environmental outcome or action is purchased from a provider, if and only if the outcome or action is delivered (Gibbons et al., 2011; Wunder, 2005; Wunder et al., 2008). In a marine context this could involve payments to: protect or release threatened species (Leduc \& Hussey, 2019; Wosnick et al., 2020), reduce fishing effort in an area of important marine habitat (Sykes et al., 2018), compensate for lost earnings due to harvest restrictions, or restore coastal habitat (Mohammed, 2012). PES already has been widely applied in terrestrial conservation, with theory and practice indicating that PES can be efficient and effective, and, when well designed, can benefit biodiversity and alleviate poverty (Ferraro \& Simorangkir, 2020; Ma et al., 2017). Yet PES remains under-explored and under-utilized in the marine realm (Bladon et al., 2016). Some possible reasons for this include difficulty in clearly defining and monitoring marine ES and their provision; lack of clear property rights; and limited demand for marine ES from buyers (Booth, Arlidge, et al., 2021; Mohammed, 2012).

However, with growing adoption of net-outcome goals for biodiversity (CBD, 2020; Maron et al., 2021), regulatory and compliance markets for marine ES are developing. Biodiversity offsets are increasingly mandated by governments and investors (Bull \& Strange, 2018; Shumway et al., 2018), and just as consumers and shareholders are increasingly demanding deforestation-free and carbon-neutral terrestrial supply chains, so too could they demand biodiversity-neutral seafood supply chains and coastal development projects (Booth, Arlidge, et al., 2021; Jouffray et al., 2019). This will require entities which damage marine biodiversity to offset their impacts through measurable, additional biodiversity outcomes. Therefore, a supply of investment-ready marine 
conservation projects will be needed - which can demonstrate measurable, additional marine conservation outcomes for a given cost - to achieve net outcomes in the marine realm under the CBD's post-2020 strategy (CBD, 2020; Jacob et al., 2020). Marine PES projects could play an important role in meeting this demand, as part of a wider instrument mix to mitigate bycatch and restore bycatch-affected populations (Booth, Arlidge, et al., 2021; Innes et al., 2015).

Yet in order to be successful PES programs must be carefully designed according to their ecological, socioeconomic and institutional conditions (Wunder et al., 2008), with contextually rich evidence to inform robust intervention design (Christie et al., 2020; Mohammed, 2012; Wyborn \& Evans, 2021). However, empirical data are lacking on whether PES would be accepted by coastal communities; if PES can deliver marine conservation and well-being outcomes; and how they should be designed. Economic theory and fisher behaviour indicate that conditional monetary rewards and exogenously-imposed rules and sanctions can influence marine resource extraction (Arias et al., 2015; Booth et al., 2020; Gutiérrez et al., 2011; Wosnick et al., 2020). However, theories of collective action show that trust, norms and institutional arrangements also shape individual behaviour in ways that differ from those predicted by rational self-interest (Ostrom, 1990, 2000). Therefore, rules and incentives can crowd-out or crowd-in pro-social behaviour depending on their perceived legitimacy, with complex interactions between intrinsic and extrinsic incentives depending on the institutional and social context (Cinner et al., 2021; Gneezy et al., 2011; Grillos et al., 2019; Oyanedel et al., 2020). Given this uncertainty and complexity, predictive solutions-focused approaches are needed to understand a) how different types of incentive-based interventions might influence fisher behaviour and resulting outcomes, and b) the relative cost and cost-effectiveness of different interventions (Travers et al., 2019; Williams et al., 2020). This can help to test assumptions, identifying factors upon which the success of interventions depend, guard against unintended social and ecological consequences, and ultimately ensure that limited resources are not wasted (Ferraro \& Pattanayak, 2006; Travers et al., 2019, 2021).

Within this need and context we used predictive methods from conservation and behavioural sciences (Travers et al., 2019, 2021) - adopting a novel combination of scenario interviews (Cinner et al., 2009; Travers et al., 2019) and contingent valuation (CV) (Carson \& Hanemann, 2005) - to understand how incentive-based mechanisms 
might influence fisher behaviour, and resulting conservation and well-being outcomes, in SSFs. This combination

110 of methods is particularly useful since it can provide quantitative estimates of the cost-effectiveness of incentive-

111 based interventions, and qualitative details on why certain interventions might be (in)effective based on fishers'

112 attitudes, preferences, and motivations, both of which are needed for appropriate PES design.

114 We implemented the research in Indonesia: a global priority country for reconciling trade-offs between marine 115 biodiversity and fisheries (Selig et al., 2014, 2018); and focused on two Critically Endangered (CR) and CITES116 listed taxa (hammerhead sharks (Sphyrna spp.) and wedgefish (Rhynchobatus spp.)) in two case study SSFs. In doing 117 so we aimed to answer the following management-relevant questions:

118 1. What is the potential effectiveness and cost-effectiveness of performance-based positive incentives for 119 changing fishers' behaviour relating to capture and retention of CR marine megafauna (and delivery of 120 associated biodiversity and well-being outcomes), and how does this compare with other counterfactual scenarios (including business as usual, negative incentives (i.e., fines) and non-monetary social rewards)?

2. Which factors might influence implementation and effectiveness of incentive-based approaches in SSFs?

3. What are some of the underlying mechanisms (how) and motivations (why) for changes in behaviour?

Answers to these questions can be used within the study sites, to identify which types of interventions and instrument mixes might be most cost-effective for reducing mortality of CR marine megafauna, whilst maintaining or improving well-being of coastal communities. More broadly our results can build a greater understanding of values of marine species from the perspective of resource users, which can in turn be used to inform multi-use resource management plans and prices of marine biodiversity offsets (Booth, Arlidge, et al., 2021; Lew, 2015). Our methods can also be applied to other similar SSFs throughout the world - to provide contextually rich evidence for local intervention design and global financing mechanisms that could deliver net positive outcomes and a sustainable and equitable ocean economy (Bennett et al., 2019; Booth, Arlidge, et al., 2021; Christie et al., 2020). 


\section{Methods}

136 Study taxa and sites

137 We focused on understanding fishers' landings of hammerheads and wedgefish in two case study SSFs in

138 Indonesia: Lhok Rigaih (LR) in Aceh Jaya, Aceh Province, and Tanjung Luar (TL) in East Lombok, East Nusa

139 Tenggara Province (Figure 1), and the conservation and well-being outcomes that result from changes in this

140 behaviour under different plausible incentive-based interventions.

142 We chose these study taxa since both are Critically Endangered and CITES-listed, yet they are commonly caught 143 throughout tropical SSFs as a source of food and income; they also represent contrasting case types in terms of 144 biological traits, catchability, survivability and use values (Hau et al., 2018; Kyne et al., 2020; Rigby et al., 2019; 145 Wu, 2016) (S1).
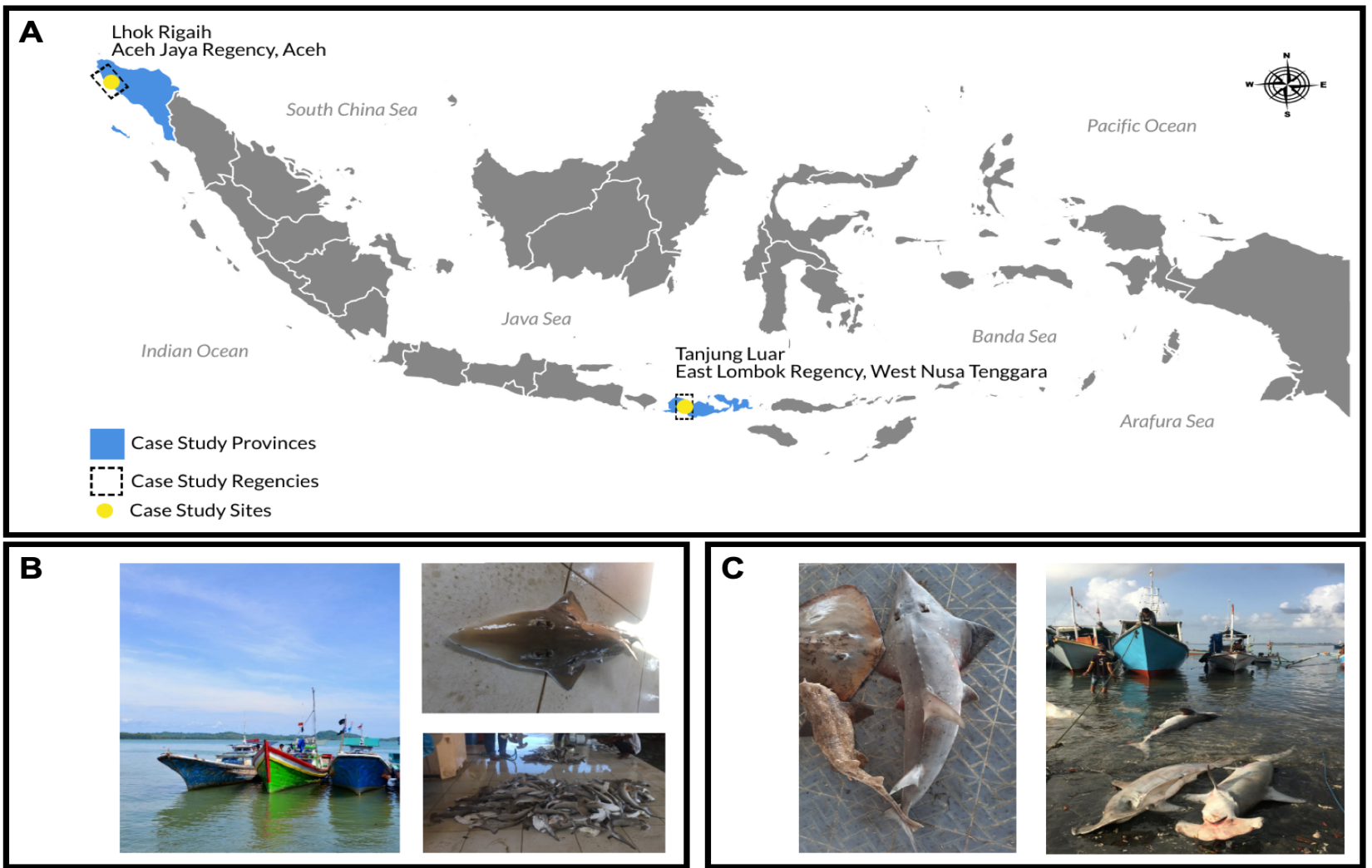

148 Figure 1 Study sites. A) Map of Indonesia, with location of study sites, B) Example study vessels (left) and landings (right) from LR, 149 C) Example study vessel (right, see larger blue vessel) and landings from TL 
151 We chose the study sites as known landing site for hammerheads and wedgefish, with these taxa playing important roles in the livelihood strategies of local fishers (Booth, Ichsan, et al., 2021; Booth, Squires, et al., 2021; Simeon, Fajri, et al., 2020; Yulianto et al., 2018). Efforts have also been made to implement more traditional conservation interventions in LR and TL, such as exploring alternative livelihoods and establishing marine protected areas, yet these approaches have been unsuccessful in significantly mitigating catches of hammerheads and wedgefish, suggesting that a novel approach is required (Booth et al., 2018; Simeon, Fajri, et al., 2020; Simeon, Ula, et al., 2020). Finally, the sites also represent contrasting case types in terms of ecological, socioeconomic, and institutional conditions, allowing for cross-case comparison (S1). LR is a coastal gillnet fishery where primarily juvenile elasmobranchs are caught as marketable incidental catch alongside reef fish, demersal fish and lobster (Simeon, Fajri, et al., 2020). Hammerheads and small wedgefish in LR are mainly used for local consumption, while large wedgefish, which are caught infrequently, can reach values of IDR $1-2$ million per individual ( US\$70 - 140) because their large fins can be exported for the international fin trade (Booth, Ichsan, et al., 2021; Hau et al., 2018) (S1). In contrast TL is a semi-commercial pelagic longline fishery taking a mixture of elasmobranch species as target catch (WCS-IP, 2019; Yulianto et al., 2018) (S1). Hammerheads and wedgefish caught in in TL are typically adults or sub-adults. The fins are primarily for high-value export, while meat and other commodities (skin, cartilage, liver oil) are consumed locally or domestically (Booth, Squires, et al., 2021; Yulianto et al., 2018) (S1).

\section{Study design}

We used a novel combination of scenario interviews and contingent valuation (CV) to answer our research questions (S2). Scenario interviews are commonly used in behavioural sciences and predictive conservation, and involve constructing a set of plausible futures and asking people how they would behave and why (Cinner et al., 2011; Travers et al., 2016, 2019). CV is a well-established stated preference method of economic valuation, which can be used to estimate preferences for and costs of hypothetical policies; and the value of public environmental goods, including marine species (Carson \& Hanemann, 2005; Lew, 2015; Vianna et al., 2018). As such, this combination of methods can be used to estimate both the effectiveness and cost-effectiveness of incentive-based approaches, and underlying drivers and mechanisms of behaviour change. 
Interview structure

Each interview included a pre-survey to collect socio-demographic information and ensure familiarity with the study taxa, followed by exploration of four scenarios $($. The order in which each taxa and the scenarios were presented was randomized to control for question-ordering biases.

Table 1) for each taxon with CV questions embedded into scenarios regarding direct monetary incentives.

For the scenarios we followed a similar design to Travers et al. $(2016,2019)$ enabling comparison of the relative effects of different hypothetical interventions on conservation-relevant behaviour by considering multiple scenarios within the same study. Specifically, we examined the effect of three hypothetical interventions on fishers' landings of hammerhead sharks and wedgefish relative to business as usual (BAU) (. The order in which each taxa and the scenarios were presented was randomized to control for question-ordering biases.

Table 1). The hypothetical interventions were designed based on a scoping phase to ensure suitability and plausibility, and included: 1) direct, positive, performance-based monetary incentives (i.e. PES), 2) direct negative monetary incentives, implemented via a regulation and associated sanction (i.e. a fine), 3) a site-specific intervention, based on an understanding of fishers' interests and priorities developed during the scoping phase: fishers in TL were offered an indirect monetary reward via a lottery for children's school fees (scoping research indicated fishers in TL highly value their children's' education); fishers in LR were offered non-monetary social rewards via community recognition (previous research indicated some existing intrinsic and social motivations for conservation (Booth, Ichsan, et al., 2021)) (. The order in which each taxa and the scenarios were presented was randomized to control for question-ordering biases.

Table 1, S2). The order in which each taxa and the scenarios were presented was randomized to control for question-ordering biases.

Table 1 Scenarios explored in the scenario interviews. A fine and PES scenario was explored in both sites, as well as a site-specific intervention in each site, designed based on a qualitative understanding of fishers' interests and motivations as per findings during the scoping phase.

\begin{tabular}{|l|l|l|}
\hline \multirow{2}{*}{ Scenario } & \multicolumn{1}{|c|}{ Tanjung Luar (N = 120) } & \multicolumn{1}{c|}{ Lhok Rigaih (N = 22) } \\
\cline { 2 - 3 } $\begin{array}{l}\text { Business as } \\
\text { Usual (BAU) }\end{array}$ & Everything continues the same as it is now, with no changes in markets or regulations. \\
\hline $\begin{array}{l}\text { Positive } \\
\text { incentive } \\
\text { intervention } \\
\text { (PES) }\end{array}$ & $\begin{array}{l}\text { An agreement is established to provide direct performance-based compensatory payments } \\
\text { for any vessels returning from a fishing trip with zero hammerhead sharks/wedgefish. } \\
\text { Someone will be monitoring the port every day, and fishers will be required to provide } \\
\text { additional proof of compliance, such as on-board video monitoring during their trip. }\end{array}$ \\
\hline
\end{tabular}




\begin{tabular}{|l|l|l|}
\hline $\begin{array}{l}\text { Negative } \\
\text { incentive } \\
\text { intervention } \\
\text { (Fine) }\end{array}$ & $\begin{array}{l}\text { A law is established to fully protect hammerhead sharks/wedgefish, and any vessel found } \\
\text { landing a hammerhead sharks/wedgefish would be fined. Someone will be monitoring the } \\
\text { port every day, and the fine will be taken from the total trip profit. }\end{array}$ \\
\hline \multirow{3}{\text{Site-specific}}{$\begin{array}{l}\text { intervention } \\
\text { Lottery: An agreement is established for an } \\
\text { education fees lottery scheme, so that } \\
\text { members of all vessels returning from a fishing } \\
\text { trip with zero hammerhead sharks/wedgefish } \\
\text { enter a monthly lottery in which the prize is } \\
\text { school fees payments for 1 year for a school- } \\
\text { aged child in their family. Someone will be } \\
\text { monitoring the port every day, and fishers will } \\
\text { be required to provide additional proof of } \\
\text { compliance such as on-board video monitoring } \\
\text { during their trip. }\end{array}$} & $\begin{array}{l}\text { Guardians: A 'shark guardians' group is } \\
\text { established in which participating fishers } \\
\text { voluntarily agree to land zero } \\
\text { hammerhead sharks/wedgefish. In return } \\
\text { they receive specialized training and } \\
\text { equipment, public social recognition in } \\
\text { local newsletters and media channels, and } \\
\text { invitations to monthly events with other } \\
\text { shark guardians and local leaders. }\end{array}$ \\
\hline
\end{tabular}

205 For each scenario questions focused on understanding: 1) changes in landings of the study taxon (increase, no 206 change, decrease), 2) the magnitude of the positive/negative incentives needed to induce changes in landings of 207 that taxon (i.e., the Willingness-to-Accept (W'TA) a payment and the Willingness-to-pay (WTP) a fine) using a CV 208 question for the PES and fine scenarios, and 3) how and why fishers would change their behaviour using 209 structured and open-ended follow-up questions (S2).

For CV questions we used the payment card method, in which respondents selected their minimum WTA/WTP

212 to reduce their landings to zero from a range of bid values (S2). We designed the CV questions to reduce common 213 biases, including: 1) pre-surveying and piloting bid ladders, to optimize efficiency and accuracy of responses while 214 minimizing cognitive burden (the survey was first piloted with 4 Indonesian Masters students, and then with 4 ex215 shark fishers in TL, and 4 gillnet fishers in the next village to LR); 2) including an adapted version of a cheap talk 216 script (i.e., describing the propensity of respondents to exaggerate stated WTP, and the potential consequences 217 thereof (S2)) to reduce hypothetical bias/increase perceived consequentially; 3) asking follow-up questions on zero responses, to separate true zeros from protest zeros; 4) randomizing the order in which the bid values were presented (i.e. low-to-high vs high-to-low) amongst participants to control for anchoring bias (Carson \& Hanemann, 2005).

For understanding mechanisms we asked fishers how they would change their landings, with answers on catch mitigation grouped into three categories based on the mitigation hierarchy (Booth et al., 2019a; Milner-Gulland et al., 2018): 'avoid' (e.g., by changing gear or fishing ground), 'minimize' (e.g., by reducing effort) or 'remediate' (i.e., 
post-capture release). For those that mentioned post-capture release we asked a further follow-up question on

perceived survivability using a 5-point Likert scale ranging from always dead (-2) to always alive (2) (S2). To

understand motivations, we asked fishers why they would reduce their landings. We focused in particular on

perceived fairness and impacts on material well-being of each scenario, as both are determinants of the social

legitimacy of rules, people's willingness to comply, and the socio-economic impacts of conservation (Arias et al.,

2015; Keane et al., 2008; Oyanedel et al., 2020). We used 5-point Likert-scale questions (ranging from very fair (2)

to very unfair (-2) and large positive impact on household income (2) to large negative impact (-2)) followed by open-ended questions for fishers to explain their answers further, which provided qualitative details and allowed triangulation of answers to check for consistency (S2).

Data collection

Interviews were conducted during site visits from December 2019 to July 2021, primarily in Bahasa Indonesia and with local languages occasionally used for clarification purposes. We interviewed 142 fishers in total, including 120 from TL and 22 from LR, representing roughly $90 \%$ of the shark-relevant fisher population in both locations.

Data was collected under a foreign research permit (No. Surat Izin: 407/ E5/E5.4/SIP/2019), with ethical review and approval from the Interdivisional Research Ethics Committee at the lead author's institution (MS IDREC, ref. R66416/RE001).

Analysis

Question 1. Estimating effectiveness and cost-effectiveness of incentives

We used descriptive statistics to summarize and compare stated responses regarding changes in landings under each hypothetical scenario. Results for each scenario were compared against BAU and each other following Travers et al. $(2016,2019)$.

For the scenarios involving incentives (PES and fine) we derived median WTA and WTP per site and taxon from CV responses. We then used median WTAs and WTPs coupled with existing data on average catches and trip numbers to estimate a) the economic value of wedgefish and hammerheads according to fishers in the two sites, b) the potential annual costs of PES interventions for each taxon and site, and c) the estimated cost effectiveness 
253 in terms of total mortality mitigated per dollar spent for each site. For TL, these estimates were based on an 254 average of $\sim 300$ fishing trips per year, which land 1.7 hammerhead sharks per trip; and $\sim 140$ trip per year which land 0.97 wedgefish per trip (WCS-IP, 2019). For LR, there are $~ 1,560$ shark-relevant trips per year, which land an average of 11.5 hammerheads and 1.4 wedgefish per trip (Simeon, Fajri, et al., 2020). We also compared median stated preferences with other independent market values for validation purposes.

\section{Question 2. Identifying factors which influence willingness to change}

260 We constructed models to analyze the effects of the different scenarios and taxa - alongside other socioeconomic, demographic, contextual and study design control variables (Table 2) - on stated willingness to change behaviour (i.e., reduce landings). This enabled validation, by testing whether responses correlated as expected with externally valid constructs (e.g., economic value, opportunity costs, Table 2); and exploration, to understand which socio-demographic and contextual factors might influence (cost) effectiveness of incentive-based approaches.

We used mixed-effects logistic regression with a binary response variable for would (1) or would not (0) reduce landings. We used scenario and taxa as predictor variables and explored the influence of all other meaningful control variables (Table 2) on how well the model fit the data using backwards selection to find the optimal model with the lowest Akaike information criterion value (S3). We excluded the site-specific scenarios to allow for meaningful cross-site comparison, resulting in 567 observations from 189 interviewees. We used 'interviewee' as a random effect to account for pseudo-replication introduced through survey participants providing responses to multiple scenarios, and tested models for each scenario and taxon separately to check for consistency. Modelling was conducted in RStudio using the glmer function in the lme4 package (Bates et al., 2015). We also constructed linear models of WTP and WTA, and conducted Welch Two Sample t-tests to investigate whether predictors of and differences in means were as expected (Table 2) (S4).

We expected PES and fine scenarios to have positive associations with willingness to change behaviour relative to

BAU. We expected fishers' catches of the study taxa and incomes to correlate negatively with willingness to change and WTA, as proxies for perceived or actual use values and thus opportunity costs of reducing landings. 
280 Fishers in TL were expected to have higher WTA/WTP relative to LR, based on differences in fishery types and

281 market access (S1). All other variables were included as control or exploratory variables (Table 2).

282 Table 2 Explanatory variables included in a mixed-effects logistic regression with a binary response variable, indicating if respondents 283 said they would (1) or would not (0) reduce landings.

\begin{tabular}{ll}
\hline Variable & Description \\
\hline Scenario & $\begin{array}{l}\text { Categorical variable representing } \\
\text { the hypothetical interventions } \\
\text { explored in the scenarios. Three } \\
\text { levels: BAU, fine, PES, with } \\
\text { BAU as the reference level. }\end{array}$ \\
Taxa & \\
& $\begin{array}{l}\text { Categorical variable representing } \\
\text { the taxa explored in the } \\
\text { scenarios. Two levels: } \\
\text { hammerhead or wedgefish, with } \\
\text { hammerhead as the reference } \\
\text { level. } \\
\text { Categorical variable representing } \\
\text { the sites in the study. Two levels: } \\
\text { TL and LR, with LR as the } \\
\text { reference level. Captures } \\
\text { operational and socio-economic } \\
\text { variation at the fishery-level. }\end{array}$
\end{tabular}

Last catch Continuous variable representing stated last catch of taxa in question.

Expected results, based on theory and previous Included empirical studies in optimal model?

(+) PES and fine scenarios expected to have higher Yes likelihood of behaviour change relative to BAU, according to basic economic theory and since fishers are motivated by exogenous incentives (Booth et al., 2020; Gutiérrez et al., 2011; Wosnick et al., 2020). WTA PES expected to be higher than WTP fine, due to loss aversion (Cinner, 2018; Kahneman \& Tversky, 1979).

(?) Wedgefish are more valuable per individual (Booth, Yes Squires, et al., 2021; Hau et al., 2018), however hammerheads are caught in higher total volumes in both sites (Simeon, Fajri, et al., 2020; Yulianto et al., 2018).

(+) TL expected to have higher WTA relative to LR, No since shark fishing is more targeted, commercialized and of higher value than in LR (Booth, Squires, et al., 2021; Yulianto et al., 2018).

(-) Last catch expected to correlate negatively with Yes likelihood of behaviour change and positively with WTA, as a proxy for fishers' use values for hammerheads and wedgefish, and thus perceived opportunity costs of reducing catches to zero (Carson et al., 2001; Liebe et al., 2011).

Income Continuous variable representing stated monthly household income.

(-) Income expected to correlate negatively with likelihood of behaviour change and positively with WTA. According to basic economic theory and empirical studies of WTP for environmental goods, income typically positively correlates with WTP (Carson et al., 2001; Liebe et al., 2011). However, use of the good is also important, and in this instance, income is indicative of direct use value of catches, and therefore a proxy for opportunity costs of reducing landings.

Age Continuous variable representing fisher age in years, also a proxy for experience (co-varies with fisher experience).

Fisher Continuous variable representing experience fisher experience in years (covaries with age).

(?) Included as a demographic control variable. No strong pre-existing theory or hypothesis. May serve as a proxy for generational cultural differences and potential openness to innovation.

(?) Included as a demographic control variable. No strong pre-existing theory or hypothesis. May serve as a proxy for fisher knowledge/skill, and openness to innovation.

No 
Education

Binary variable representing education level in terms of whether or not the fisher completed high-school.

\section{Influence Numerical dummy variable score representing fishers' perceived influence over fishing decisions. Three levels: $1=$ no influence, 2 = some influence, $3=$ ultimate influence, with no influence as reference level (co-varies with vessel position).}

Vessel Categorical variable representing position fishers' position in their vessel. Two levels: captain and crew, with captain as reference level. (co-varies with influence score)

Order

Numerical dummy variable representing the order in which the scenarios were presented.

Interviewee Unique identifier for each interviewee
(?) Included as a demographic control variable. No No strong pre-existing theory or hypothesis. May serve as a proxy for openness to innovation.

(?) Included as a control variable for vessel-level No decision-making dynamics. No strong pre-existing theory or hypothesis. May serve as a proxy for trust in other people's cooperation under theories of public goods and collective action.

?) Included as a control variable for vessel-level

No decision-making dynamics. No strong pre-existing theory or hypothesis. May influence perceived or actual use values/opportunity costs, since vessel captains typically receive higher incomes/greater shares of trip profits.

(?) Included to control for study design effects. Would expect a significant co-efficient if there was a significant question-ordering effect.

Included as random effect to control for pseudoreplication caused by multiple treatments for each interviewee.

Key: BAU = business as usual; PES = payment for ecosystem service, WTA = willingness to accept, WTP = willingness to pay, $+=$ expected positive association, $-=$ expected negative association, $?=$ unclear direction of association.

We used descriptive statistics to identify the most common approaches for how fishers would reduce landings, and perceptions of survivability. We also used descriptive statistics to understand overall perceptions of fairness and impacts on material well-being for each scenario, as indicators of fishers' motivations for (not) changing their behaviour, and potential well-being outcomes. For unstructured follow-up questions (i.e., where we asked fishers to further explain answers to the structured questions) we used post-hoc thematic analysis (coding and grouping) following guidelines from Braun \& Clarke (2006).

296 Throughout the study we conducted cross-case comparisons for the two taxa and sites (Yin, 2003) to understand

297 how biological, market and contextual factors may influence intervention design. 
The estimated effectiveness and cost-effectiveness of incentives

\section{Business As Usual}

Most fishers in TL stated that catches of hammerheads and wedgefish would increase in a BAU scenario $(86 \%$ of respondents and $92 \%$ of respondents, respectively; Figure 2), while most fishers in LR states that catches would remain stable (64\% and $73 \%$, respectively; Figure 2$)$.

\section{Positive Incentives (PES)}

The PES scheme had the largest predicted effectiveness in both sites (Figure 2A). In TL, 98\% and 92\% of fishers would reduce landings of hammerheads and wedgefish to zero given a payment of IDR 5 million (US\$ 357) and IDR 8 million (US\$ 571) (median CV bid per trip, respectively) (Table 4, Figure 2). In LR, 100\% of respondents would reduce landings for both taxa at median payments of IDR 300,000 (US\$21) and IDR 150,000 (US\$ 10) per trip for hammerheads and wedgefish, respectively (Table 4, Figure 2).

\section{Negative incentives (fine)}

In contrast, $54 \%$ and $64 \%$ of fishers in TL would reduce landings of hammerheads and wedgefish (respectively) in response to a fine. Effectiveness was lower in LR at 18\% and 27\%, respectively (Figure 2A). Correspondingly, many respondents gave protest zeros in the CV question ( $42 \%$ and $36 \%$ for hammerheads and wedgefish in TL, and $82 \%$ and $73 \%$ in LR, respectively (S5)). For those that did state a WTP, median bids per trip for hammerheads and wedgefish were IDR 2 million (US\$ 143) and IDR 1.5 million (US\$107) in TL, and IDR 45,000 (US\$ 3) and IDR 80,000 (US\$ 6) in LR (respectively) (Figure 2).

\section{Site-specific scenarios}

The school fees lottery scenario in TL was the least effective: just $50 \%$ of fishers stated that they would reduce landings (Figure 2). The guardians scenario in LR was more effective than the fine but less effective than PES: $55 \%$ and $27 \%$ of fishers would voluntarily reduce wedgefish and hammerhead landings, respectively (Figure 2). 
326 Based on the median CV bids we estimate that fishers in TL attribute economic values of $\$ 83$ - $\$ 210$ per 327 individual hammerhead and $\$ 110$ - 588 per individual wedgefish For fishers in LR, the estimated values are $\$ 0.38$ $328-1.80$ per hammerhead shark and $\$ 4.01-7.64$ per wedgefish (Table 3). These results are directionally consistent 329 with expectations (S4) and other independent studies (Booth, Squires, et al., 2021; Hau et al., 2018; Wu, 2016). 330 Based on available data on trips per year, it would cost $\$ 42,330-107,100$ to implement a PES scheme to 331 incentivize fishers to stop landing hammerheads in TL, and \$5,382 - 32,292 in RL (Table 3). This could save an 332 estimated 500 adult or sub-adult sharks per year in TL and up to 18,000 juveniles per year in LR (assuming 100\% 333 uptake, and relative to the 2021 baseline). To implement the same for wedgefish would cost $\$ 14,938-79,850$ in 334 TL (saving around 140 adult individuals) and \$8,758- 16,685 in LR (saving over 2,000 sub-adult individuals) 335 (Table 3). 


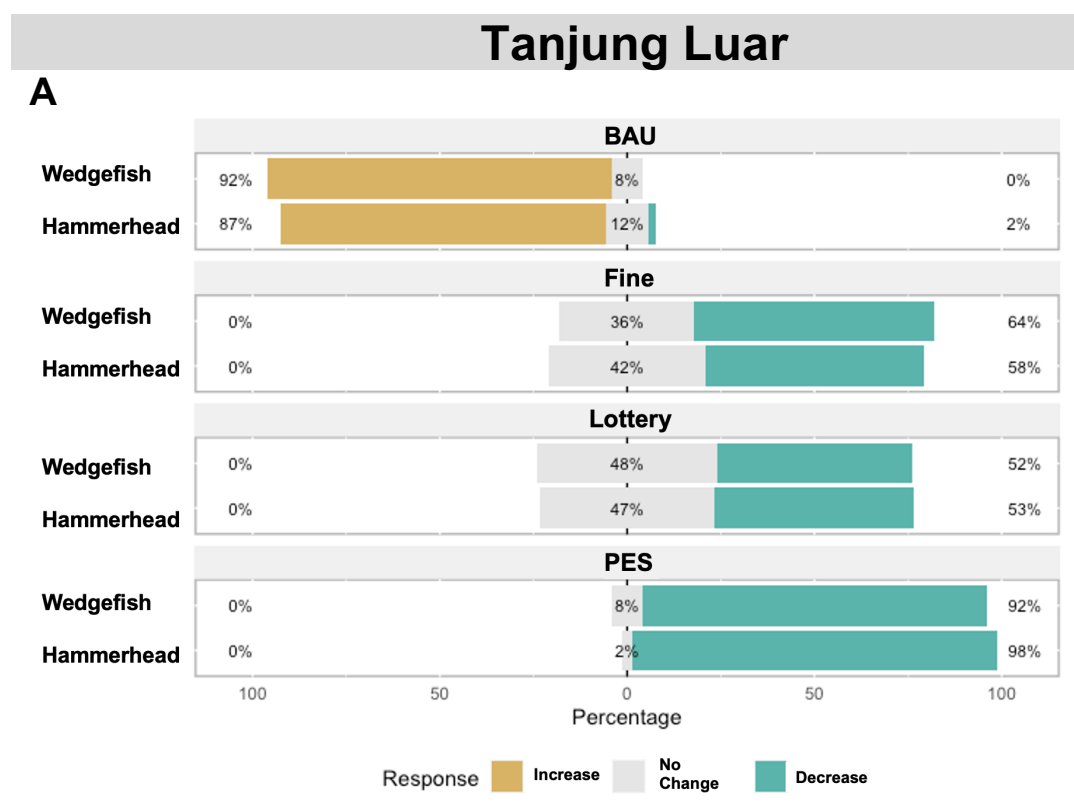

\section{Lhok Rigaih}

B
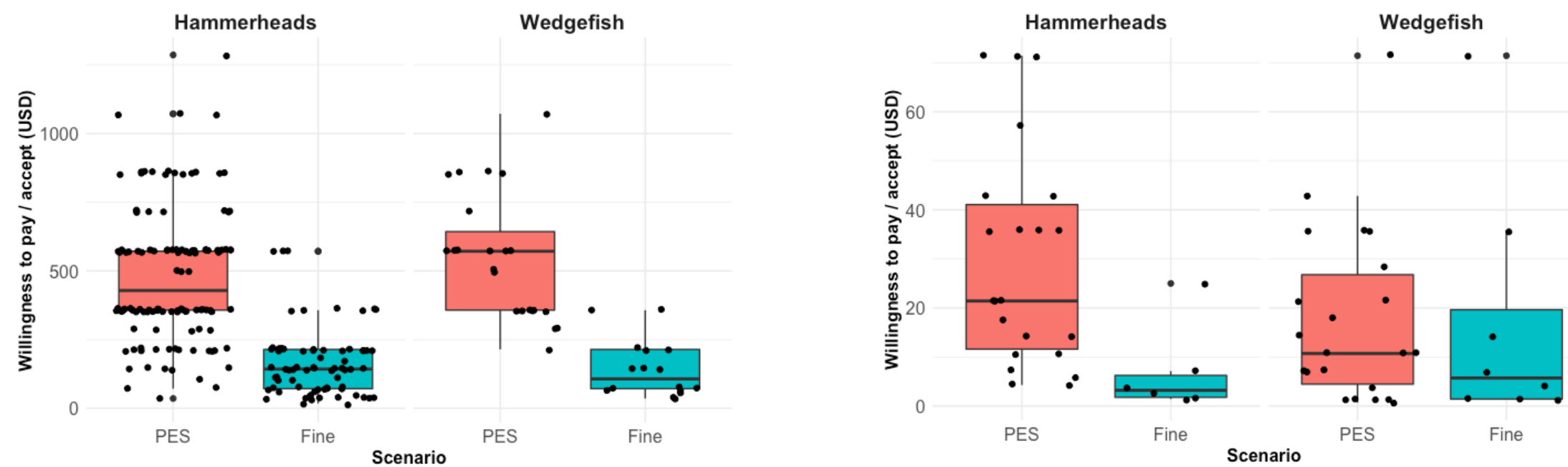

Figure 2. Fishers' responses to different hypothetical interventions for managing capture of hammerhead sharks and wedgefish in Tanjung Luar (left) and Lhok Rigaih (right). A) reported changes in landings under different scenarios, B) median and spread of minimum WTA/maximum WTP under PES and Fine scenarios based on contingent valuation. Exchange rate at IDR 14,000 $=$ USD 1.00. BAU $=$ business as usual; PES $=$ payment for ecosystem service. 
Table 3 Value estimates per individual shark. (USD), based on fishers' stated willingness to accept (WTA) and willingness to pay (WTP). Value per individual is calculated based on average catches of 1.7 hammerheads and 0.97 wedgefish per trip in TL, and 11.5 hammerheads and 1.4 wedgefish per trip in LR. Value per year based on average annual shark-relevant trips of 300 for hammerheads and 140 for wedgefish in TL, and 1,560 for both taxa in LR

\begin{tabular}{|c|c|c|c|c|c|}
\hline Site & Taxon & Scenario & $\begin{array}{l}\text { Est. value per } \\
\text { trip }\end{array}$ & $\begin{array}{l}\text { Est. value per } \\
\text { year }\end{array}$ & $\begin{array}{c}\text { Est. value per } \\
\text { individual shark }\end{array}$ \\
\hline \multirow{4}{*}{ 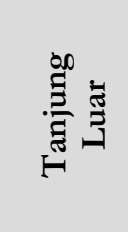 } & \multirow{2}{*}{ Hammerhead } & PES & 357 & 107,100 & 210 \\
\hline & & Fine & 142 & 42,600 & 83 \\
\hline & \multirow{2}{*}{ Wedgefish } & PES & 571 & 79,940 & 588 \\
\hline & & Fine & 107 & 14,980 & 110 \\
\hline \multirow{4}{*}{ 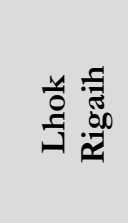 } & \multirow{2}{*}{ Hammerhead } & PES & 21 & 32,760 & 1.80 \\
\hline & & Fine & 3 & 4,680 & 0.30 \\
\hline & \multirow{2}{*}{ Wedgefish } & PES & 11 & 17,160 & 7.64 \\
\hline & & Fine & 6 & 9,360 & 4.01 \\
\hline
\end{tabular}

\section{Factors influencing willingness to change}

343 The optimal model for willingness to reduce landings included scenario, taxa, age and last catch as fixed-effects,

344 and interviewee as a random effect (Table 4, S3). Model outputs indicated that PES and fine interventions were 345 associated with a statistically significant increase in the likelihood of reducing landings compared with BAU 346 ( $\mathrm{p}<0.001$ ), with PES having the largest effect size of $99-100 \%$ probability of willingness to change (Table 4), 347 which matched expectations. Taxon was not a significant predictor of willingness to reduce landings in principle, though willingness was lower for wedgefish than hammerheads (Table 4). Last catch was significantly negatively correlated with likelihood of reducing landings $(\mathrm{p}<0.01)$ (Table 4). This result is as expected, with catches representing perceived opportunity costs of reducing landings. Fisher age also had a significant negative relationship with likelihood of reducing landings $(\mathrm{p}<0.01)$ (Table 4), and may serve as a proxy for generational differences in openness to innovation. These effects remained consistent when models were constructed with sub-sets of data (S3).

Table 4 Model outputs for influence of scenarios, taxa and socio-demographic control variables on stated willingness to change behaviour (i.e., likelihood of reducing landings of wedgefish and hammerheads to zero). Logit model coefficients converted from log odds to probabilities with 95\% confidence intervals using as per probability $=\exp ($ coeff) $/ 1+\exp ($ coeff).

\begin{tabular}{lrrrrrr}
\hline Predictor & Model coefficient & $\begin{array}{l}\text { Probability } \\
\text { estimate }\end{array}$ & \multicolumn{2}{c}{$\begin{array}{l}\mathbf{9 5 \%} \text { Confidence } \\
\text { interval }\end{array}$} & p-value & Sig \\
\hline (Intercept) & -2.450 & 0.079 & $0.013-0.354$ & 0.009 & $* *$ \\
\hline Scenario - PES (vs BAU) & 9.245 & 0.999 & $0.999-1.000$ & $2.45 \mathrm{e}^{-16}$ & $* * *$ \\
\hline Scenario - Fine (vs BAU) & 4.563 & 0.989 & $0.965-0.997$ & $7.59 \mathrm{e}^{-13}$ & $* * *$ \\
\hline Taxa - Wedgefish (vs hammerhead) & -0.107 & 0.473 & $0.287-0.667$ & 0.795 & \\
\hline
\end{tabular}




\begin{tabular}{|c|c|c|c|c|c|}
\hline Last catch & -0.092 & 0.477 & $0.460-0.495$ & 0.010 & $*$ \\
\hline Age (in years) & -0.046 & 0.489 & $0.477-0.500$ & 0.046 & $*$ \\
\hline
\end{tabular}

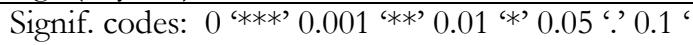

We found significant differences between TL and LR for both mean WTA payment and mean WTP fine (Welch

360 Two Sample t-tests, $\mathrm{p}<0.001$ for both WTA and WTP). Both were significantly higher in TL, which aligns with 361 expectations given the differences in market access and use values for the sites. Differences between each taxon 362 were only significant for WTP in LR, where hammerhead sharks had a higher absolute value than wedgefish 363 ( $\mathrm{p}<0.01)$, likely reflecting their higher and more frequent relative catch rates. Validation models of WTA and 364 W'TP also generally aligned with expectations (S4).

\section{Mechanisms and motivations for behaviour change: how and why}

\section{Mechanisms for changing landings (or not)}

Of those who stated they would reduce landings, most reported post-capture release as the method $(85 \%$ for hammerheads, $96 \%$ for wedgefish in TL; and 100\% for both taxa in LR, S6). However, $50 \%$ of fishers in LR stated they would only release live individuals, and others stated that they would use dead sharks as bait. In terms of survivability, $72 \%$ of all respondents across both sites reported that wedgefish are usually alive when brought on to the boat, with a further 19\% reporting they are sometimes alive (S6). In contrast, $96 \%$ of respondents from TL reported that hammerheads are sometimes alive and sometimes dead; and $86 \%$ of respondents from LR reporting that they are usually or always dead (S6). Other approaches to reduce catches were rarely mentioned but included changing fishing grounds to avoid hammerheads in TL (10\% of fishers) (S6) and indications of higher catches during certain months and areas in LR.

Those who stated they would not reduce landings also offered a range of different strategies. For example, fishers who said they were not willing to comply with a fine said they would fish more to make up the loss; hide the shark and land it elsewhere to sell; or use it as bait. 
383 The PES scenario was perceived as fair by over $95 \%$ of fishers for both sites and taxa, and to have positive 384 (96/99\% in TL) or neutral (45/59\% in LR) impacts on material well-being (Figure 3). Correspondingly, when asked to explain why they would change their landings under the scenarios most respondents $(>92 \%$ for both sites and taxa) mentioned economic reasons (e.g., "The price of sharks has been replaced, so it is enough to meet our daily needs", "the compensation can cover the operating costs"). However, in LR this was often only part of the answer, other reasons included: intrinsic motivations to protect the ocean (32\%); desire to comply with rules (14\%); and socialor community-related motivations to follow their peers (9\%) (e.g., "If others agree, I will obey", "there will be more wedgefish", "togetherness to protect the sea") (Figure 3). In contrast, no fishers in TL mentioned intrinsic or social motivations. Fishers were primarily motivated by providing resources, security, or education for their immediate 392 family.

The fine scenario was widely perceived as unfair (73-96\%) with negative impacts on well-being (67-91\%) (Figure 3), and many stated they would not comply by hiding catch or landing elsewhere. When asked to explain, fishers primarily gave economic, practical and fairness-related reasons, due to the perceived economic burden on their household and community (e.g. "it will impact our livelihoods, and be a burden on the community", "our fortune will be reduced'); or the impracticality of avoiding wedgefish and hammerheads, making it unfair if they are punished (e.g. “we cannot avoid it... it's not the target"). In LR some fishers reported that it would be wasteful and disrespectful to 400 God to release catches, especially if they are already dead (e.g., "releasing it is throwing away a gift from God", "if it's dead I will bring it home, otherwise it wastes fortune in vain").

In terms of the site-specific scenarios, the lottery scenario in TL was particularly unpopular due to perceived unfairness of the lottery itself by $>92 \%$ of fishers: only a few people would benefit, thus it would not bring large enough financial compensation. The guardians scenario in LR received mixed responses. It was perceived as fairer than a fine, but to have overall negative impacts on material well-being $(50 \% / 64 \%)$ due to lost income from catches. 


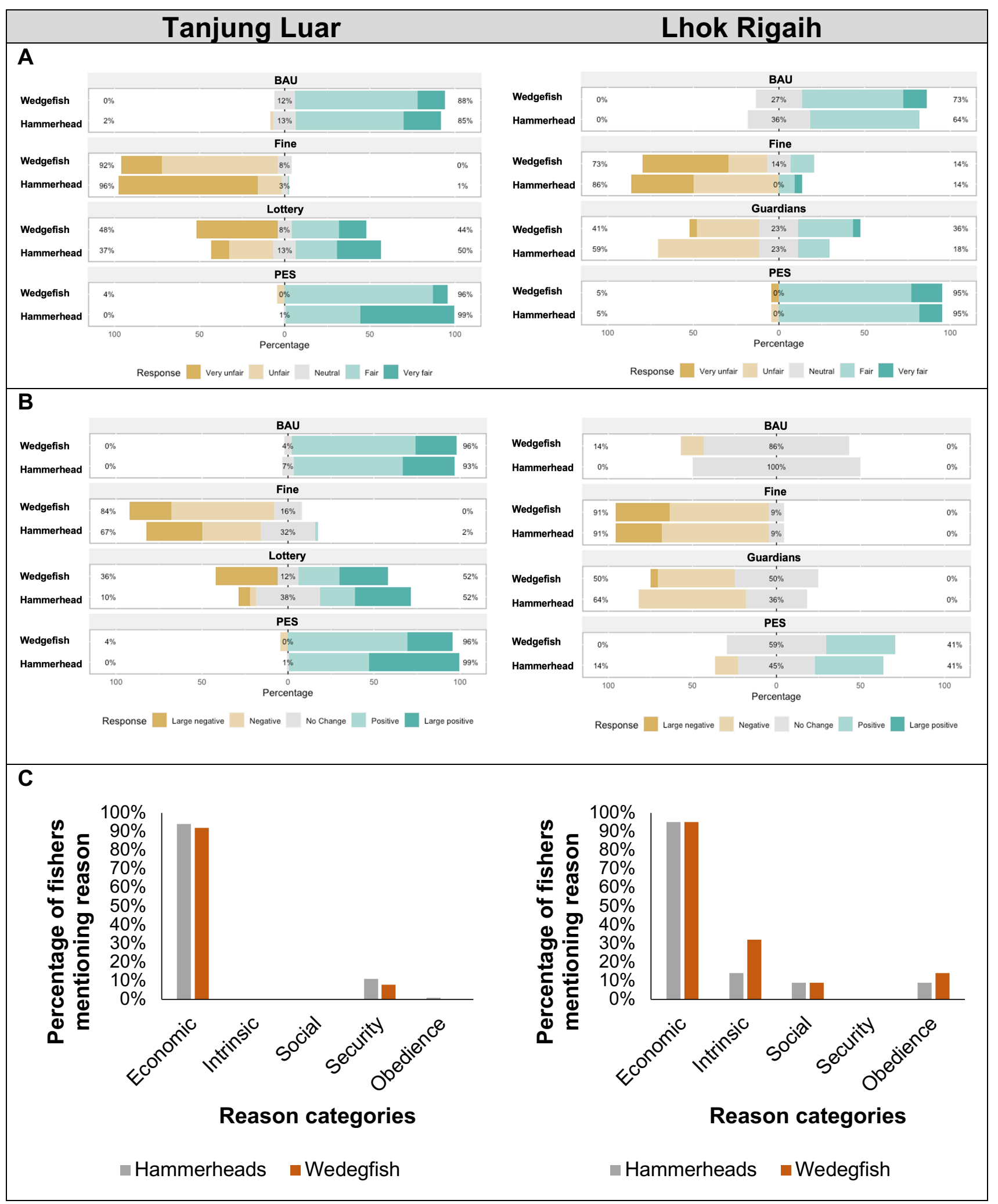

Figure 3. Summary of fishers' motivations for changing (or not chaning) their behaviour under difference scenarios in Tanjung Luar (left) and Lhok Rigaih (right). A) Perceived fairness of scenarios, B) Perceived impact of scenarios on material well-being, C) Summary of responses to open-ended questions 409 regarding reasons for changing behaviour under the PES scenario, based on post-hoc coding and grouping. 


\section{Discussion}

There is growing discourse regarding promoting equity and social justice in and through marine conservation (Bennett et al., 2019, 2021), with global environmental and sustainability goals - e.g., under the CBD and SDGs aiming to ensure that nature and people can thrive together. However, with difficult trade-offs between fisheries and conservation objectives, there remain few studies that practically and empirically demonstrate how this can be achieved. PES in SSFs offers a promising approach for mitigating damage to marine biodiversity while ensuring coastal communities are no worse off (Bladon et al., 2016; Mohammed, 2012), but there remain few real-world examples and thus limited information on if it could work, how much it might cost, and how interventions can be designed for success. Our study - which polls the opinions of people who could be most affected by marine conservation - provides empirical evidence that PES could deliver biodiversity and well-being outcomes in SSFs. The results have practical implications for our study sites, as well as broader implications on methods and approaches for delivering a sustainable and equitable blue economy, and bycatch-neutral seafood supply chains under net outcome policies (Bennett et al., 2019; Booth, Arlidge, et al., 2021; CBD, 2020; Jacob et al., 2020).

\section{Interpretation and implications}

\section{Question 1. What is the potential effectiveness and cost-effectiveness of performance-based positive} incentives, and how does this compare with other counterfactual scenarios? Positive performance-based incentives were estimated to be highly effective for changing fisher behaviour to mitigate mortality of CR species, especially when compared with BAU (99-100\% predicted effect) and more traditional instruments such as direct regulation. In terms of biodiversity outcomes, PES could save more than 20,000 CR hammerheads and wedgefish per year across the two sites (relative to 2021 baseline) for an estimated cost of $\$ U S 71,000-236,000$. This equates to an estimated cost-effectiveness of 3 - 11 individuals saved per dollar spent, and could be even higher relative to the BAU counterfactual in which many fishers said they would increase catches. In terms of well-being outcomes, PES was widely accepted by fishers as fair and having either no negative impacts or positive impacts on their material well-being. In contrast, the large proportion of negative responses to the fine scenario highlights the limitations of direct regulation and enforcement. In this case, extrinsic negative incentives may crowd-out proconservation norms, while positive incentives may crowd them in (Cinner et al., 2021; Gneezy et al., 2011; Grillos et al., 2019). This result also corroborates previous studies on non-compliance with fishing regulations that are 
perceived as unfair and illegitimate (Oyanedel et al., 2020). In some cases, civil resistance has led to regulations being rolled back (e.g. Semedi \& Schneider, 2021), or committed enforcement efforts are required (e.g. Booth et al., 2020), which may be more costly to implement than a payment scheme. demographic factors (e.g., age and perceived opportunity costs), and wider contextual and market-related factors (e.g., site and taxa) can influence effectiveness and cost of PES. This aligns with the literature on terrestrial PES

\section{Question 2. Which factors might influence implementation and effectiveness of incentive-based}

approaches? Models and statistics of factors influencing effectiveness generally aligned with theory and expectations, and indicated that incentive design (e.g., positive vs. negative incentive), individual socioschemes (Börner et al., 2017; Engel et al., 2008; Gneezy et al., 2011; Wunder et al., 2008) and underlines the importance of using grounded predictive approaches such as ours to design robust interventions.

\section{Question 3. What are some of the underlying mechanisms (how) and motivations (why) for changes in}

behaviour? Most interviewed fishers preferred post-release mitigation approaches to preventative approaches, presumably because this represents the most feasible/lowest cost option. Notably, fisher's local knowledge on mitigation and post-capture survivability generally aligned with independent studies (Gallagher et al., 2014; Simeon, Fajri, et al., 2020; Wosnick et al., 2020; Yulianto et al., 2018). Our results indicate that economic factors are a primary motivation for almost all interviewed fishers, with need to meet their daily needs and provide for their families. This helps to underline and explain why the PES approach could be particularly powerful in SSFs.

Question 4. How do these results vary across taxa and contexts? We found no significant difference between the study sites and taxa in terms of influence on willingness to change behaviour in principle (though our model included a negative but not significant co-efficient for wedgefish relative to hammerheads) (Table 3), yet clear differences in terms of WTA/WTP and thus the estimated value of PES payments required to change behaviour. The differences between TL and LR can be explained by differences in their fishery and market context, and thus the actual and perceived value of hammerheads and wedgefish. Sharks are target catches in TL. Fishers catch larger individuals, have better integration with international markets for the fin trade, and, as our study shows, are primarily economically motivated (Booth, Squires, et al., 2021; Yulianto et al., 2018). Wedgefish are also more 
valuable in TL and in international markets, and thus represent a greater opportunity cost when reducing catches

467 (Booth, Squires, et al., 2021; Hau et al., 2018). In contrast, sharks are incidental catches in LR. Fishers catch smaller individuals, and they are typically used for local consumption, and while wedgefish are more valuable per individual, catches of hammerheads are greater and more frequent, making their absolute value (i.e., per day/per trip rather than per individual) higher (Booth, Ichsan, et al., 2021; Simeon, Fajri, et al., 2020). Results from LR also indicate that intrinsic and social motivations are salient determinants of fisher behaviour (Table 4). These results highlight the more general point that monetary value is not necessarily the only determinant of people's choices (Cinner, 2018; Conlisk, 1996), and also suggests that combining social, cultural and norms-based approaches with PES could be a locally-appropriate and cost-effective intervention mix in LR, with economic motivations potentially crowding-in intrinsic motivations (Grillos et al., 2019). In contrast, the significantly higher WTAs, and no stated intrinsic reasons for pro-conservation behaviour in TL suggests strong economic motivations. In such cases, where economic motivations for exploitation are particularly strong, incentives will need to be adjusted to al., 2008).

These results can be used within the study sites to help managers and NGOs design cost-effective incentive-based interventions for reducing mortality of wedgefish and hammerheads, whilst maintaining or improving the wellbeing of fishers and their families in TL and LR. They also help to build a greater understanding of values of marine species from the perspective of resource users, which can in turn be used to inform multi-use resource management plans at the local and national level, as well prices of potential financing mechanism such as tourism levies or marine biodiversity offsets (Booth, Arlidge, et al., 2021; Lew, 2015).

More broadly our study also highlights the value of behavioural sciences, predictive methods and grounded evidence, for pro-actively exploring intervention options and gathering context-specific insights to inform management (Balmford et al., 2021; Christie et al., 2020; Travers et al., 2019; Wyborn \& Evans, 2021). We found scenarios to be a useful method for encouraging fishers to think creatively - even a hypothetical incentive revealed 
494 heterogeneity in fisher knowledge and performance, which was not otherwise mentioned in direct questioning.

495 Wider application of predictive methods such as these could support robust project design in the future (Travers 496 et al., 2019), and our methods could be easily adapted and scaled to gather grounded, context-specific data to 497 inform management across other SSFs.

499 Scaling up grounded evidence for PES is particularly important as growing adoption of net-outcome approaches 500 to marine biodiversity (e.g. under the CBD post-2020 framework and seafood sustainability strategies) lead to the 501 development of new markets and demand for measurable, additional marine conservation outcomes (Booth, 502 Arlidge, et al., 2021; CBD, 2020; Jacob et al., 2020). For example, operationalization of the polluter pays principle 503 in commercial fisheries via blue taxes could deliver no net loss or net gain, with large seafood companies required 504 to compensate for damage caused to marine biodiversity through bycatch, which could support conservation outcomes as well as distributive justice (Booth, Arlidge, et al., 2021). Studies such as this could provide the basis

506 for locally-appropriate investment-ready schemes for bycatch-neutral seafood supply chains.

508 Limitations, challenges, and implementation needs

509 Despite these opportunities, uncertainties, limitations, and practical challenges for implementation remain.

511 While our methods leverage the contextual experience of fishers, responses may not have accounted for complex 512 and unexpected feedbacks that might occur in real interventions. Exploring the extent to which fishers' 513 expectations align with real-world outcomes - for example through conducting pilots or randomized controlled 514 trials - would provide experimental evidence for real-world impact and help evaluate the predictive potential of 515 scenario-based methods. We also acknowledge other potential biases such as social desirability bias (e.g., as some 516 fishers may have been unwilling to admit that they will be deceptive), though many fishers were seemingly open 517 and honest about intentions to cheat; and cheap talk or loss aversion, which likely explain the differences in values 518 derived from WTA vs. WTP (Cinner, 2018; Grimm, 2010; Mahieu et al., 2012). Another limitation is the relatively 519 smaller sample size for LR, due to it being a smaller fishing community. In the future the study could be extended to other similar villages in Aceh Jaya to increase the sample size and allow for cross-village comparison within a similar geography and context. Despite our pilot phase to develop meaningful scenarios, we also found that the 
school fees lottery scheme in Tanjung Luar was unpopular. This was due to perceived unfairness of the lottery scheme itself rather than lack of perceived value for school fees. Our intention was to understand whether there could be a relatively higher social or non-monetary value attributed to school fees which meant fishers were willing to accept the chance element of the lottery, but this was clearly not the case. Future exploration of the potential for a lottery scheme may require expected values to be more in line with the perceived opportunity costs.

Some implementation challenges that might occur are common to all PES schemes, such as additionality, leakage and elite capture (Engel et al., 2008; Lim et al., 2017; Pascual et al., 2014); whereas others are particularly unique or challenging in the marine realm, such as monitoring and compliance management for mobile resources, lack of clear property rights, and mismatches between behaviour and conservation outcomes (i.e. reducing landings does not always translate into mortality reduction, e.g. due to post-release mortality) (Mohammed, 2012). Perverse incentives represent a further challenge, e.g., where fishers may be incentivized to increase catches or maintain unsustainable practices because they are compensated. Moving forwards, implementation of marine PES could be supported through improvements in monitoring technology (e.g. on-vessel video monitoring, machine learning, and forensic hold monitoring using eDNA (Bartholomew et al., 2018; Mangi et al., 2015), and institutional innovations which promote peer monitoring or place the burden of proof on fishers (e.g. payments conditional on video footage of live release; (Kotchen \& Segerson, 2019, 2020; Muradian, 2013). To prevent perverse incentives, payments should not exceed market values (Walker \& Townsend, 2008), and could be implemented as short-term or transitional mechanisms while efforts are made to ensure fishers adopt more sustainable practices in the longterm (e.g.,. adopting new gears with lower bycatch ratios). Strong institutions will also be required to ensure agreements are fair and are developed with free, prior and informed consent, avoid abuses of power imbalances between ES providers and financers, and facilitate equitable benefit sharing (Mohammed, 2012; Pascual et al., 2014).

Sustainable financing will also be crucial for scaling and permanence (Mohammed, 2012). Traditional marine conservation funding, such as aid and philanthropy, could be channeled directly into PES schemes, and may create more cost-effective conservation outcomes than funding indirect activities via NGOs. Novel funding sources - such as marine biodiversity offsets, tourism levies and crowdfunding - could also generate billions of 
550 dollars to finance PES (Booth, Arlidge, et al., 2021; Gallo-Cajiao et al., 2018; Jacob et al., 2020; Sykes et al., 2018).

551 PES could be particularly attractive for these emerging sources, which often require measurable conservation

552 outcomes per unit cost. As such markets emerge, the relative risk of different PES investments warrants

553 consideration. For example, out results indicate that many more individual sharks could be saved per dollar in LR

554 than in TL. However, most sharks caught in LR are juveniles, which represents a more biologically risky

555 conservation investment. One option could be to factor in the likely contribution of different life history stages to

556 population growth, and pro-rata the estimated conservation outcomes accordingly.

\section{Concluding remarks}

There are growing calls for transformative change towards a sustainable and equitable ocean economy (Bennett et al., 2019; Díaz et al., 2019), yet few robust examples of what this means in practice. PES remains a promising yet under-tested conservation intervention in the marine realm, which is a missed opportunity for delivering crossdisciplinary goals under the CBD post-2020 framework, the SDGs and the Blue Economy (Bladon et al., 2016; Booth, Arlidge, et al., 2021). Our study suggests that, if well designed, PES in SSFs could be cost-effective, and perceived as fair and socially-just from the perspective of target fishers. Based on these findings we call on NGOs, funders, researchers, policy-makers, and the private sector to forge partnerships with coastal communities, and create an enabling environment for exploring, trialing and experimentally testing marine PES projects together with small-scale fishers.

\section{Supporting Information}

569 S1. Site and taxa descriptions

$570 \quad$ S2. Survey instruments

571 S3. Modelling process for behaviour change model

572 S4. Modelling process for WTA/WTP models

573 S5. Demand curves and summary statistics for fishers' willingness to pay (WTP) fines / accept (WTA) incentives 574 S6. Summary of responses on how to reduce landings, and perceived survivability 


\section{References}

Arias, A., Cinner, J. E., Jones, R. E., \& Pressey, R. L. (2015). Levels and drivers of fishers' compliance with marine protected areas. Ecology and Society, 20(4), art19. https://doi.org/10.5751/ES-07999-200419

Balmford, A., Bradbury, R. B., Bauer, J. M., Broad, S., Burgess, G., Burgman, M., Byerly, H., Clayton, S., Espelosin, D., Ferraro, P. J., Fisher, B., Garnett, E. E., Jones, J. P. G., Marteau, T. M., Otieno, M., Polasky, S., Ricketts, T. H., Sandbrook, C., Sullivan-Wiley, K., ... Nielsen, K. S. (2021). Making more effective use of behavioural science in conservation interventions. Biological Conservation, 261(July), 109256. https://doi.org/10.1016/j.biocon.2021.109256

Bartholomew, D. C., Mangel, J. C., Alfaro-Shigueto, J., Pingo, S., Jimenez, A., \& Godley, B. J. (2018). Remote electronic monitoring as a potential alternative to on-board observers in small-scale fisheries. Biological Conservation, 219, 35-45. https://doi.org/10.1016/j.biocon.2018.01.003

Bates, D., Mächler, M., Bolker, B. M., \& Walker, S. C. (2015). Fitting linear mixed-effects models using lme4. Journal of Statistical Software, 67(1). https://doi.org/10.18637/JSS.V067.I01

Bennett, N. J., Cisneros-Montemayor, A. M., Blythe, J., Silver, J. J., Singh, G., Andrews, N., Calò, A., Christie, P., Di Franco, A., Finkbeiner, E. M., Gelcich, S., Guidetti, P., Harper, S., Hotte, N., Kittinger, J. N., Le Billon, P., Lister, J., López de la Lama, R., McKinley, E., ... Sumaila, U. R. (2019). Towards a sustainable and equitable blue economy. In Nature Sustainability (Vol. 2, Issue 11, pp. 991-993). Nature Publishing Group. https://doi.org/10.1038/s41893-019-0404-1

Bennett, N. J., Katz, L., Yadao-evans, W., Ahmadia, G. N., Atkinson, S., Ban, N. C., Dawson, N. M., Vos, A. De, \& Bennett, N. J. (2021). Advancing Social Equity in and Through Marine Conservation. Frontiers in Marine Science, 8(July), 1-13. https://doi.org/10.3389/fmars.2021.711538

Bladon, A. J., Short, K. M., Mohammed, E. Y., \& Milner-Gulland, E. J. (2016). Payments for ecosystem services in developing world fisheries. Fish and Fisheries, 17(3), 839-859. https://doi.org/10.1111/faf.12095

BMIS. (2021). Mitigation Techniques. Bycatch Mitigation Information Sytems. https://www.bmisbycatch.org/mitigation-techniques

Booth, H., Arlidge, W. N. S., \& Squires, D. (2021). Bycatch levies could reconcile trade-offs between blue growth and biodiversity conservation. Nature Ecology \& Evolution. https://doi.org/10.1038/s41559-021-01444-w

Booth, H., Ichsan, M., Hermansyah, R. F., Rohmah, L. N., Naira, K. B., Adrianto, L., \& Milner-Gulland, E. J. 

(2021). A socio-psychological approach for understanding and managing bycatch in small-scale fisheries. OSF Preprints. https://doi.org/10.31219/OSF.IO/P4AHZ

Booth, H., Mardhiah, U., Siregar, H., Hunter, J., Giyanto, Putra, M. I. H., Marlow, J., Cahyana, A., Boysandi, Demoor, A. Y. L., Lewis, S., Adhiasto, D., Adrianto, L., \& Yulianto, I. (2020). An integrated approach to tackling wildlife crime: impact and lessons learned from the world's largest targeted manta ray fishery. Conservation Science and Practice, 1-18. https://doi.org/10.1111/csp2.314

Booth, H., Muttaqin, E., Mardiah, S., Adhiasto, D., Lestari, P., \& Kassem, K. (2018). Diversiffing Indonesian fisheries to protect elasmobranchs and alleviate poverty. https://www.darwininitiative.org.uk/documents/DAR22008/24522/22-008 FR edited.pdf

Booth, H., Squires, D., \& Milner-Gulland, E. J. (2019a). The mitigation hierarchy for sharks : A risk-based framework for reconciling trade-offs between shark conservation and fisheries objectives. Fish and Fisheries, November, 1-21. https://doi.org/10.1111/faf.12429

Booth, H., Squires, D., \& Milner-Gulland, E. J. (2019b). The neglected complexities of shark fisheries, and priorities for holistic risk-based management. Ocean \& Coastal Management, $182($ September), 104994. https://doi.org/10.1016/j.ocecoaman.2019.104994

Booth, H., Squires, D., Yulianto, I., Simeon, B., Muhsin, Adrianto, L., \& Milner-Gulland, E. (2021). Estimating economic losses to small-scale fishers from shark conservation: A hedonic price analysis. Conservation Science and Practice, June, e494. https://doi.org/10.1111/csp2.494

Börner, J., Baylis, K., Corbera, E., Ezzine-de-Blas, D., Honey-Rosés, J., Persson, U. M., \& Wunder, S. (2017). The Effectiveness of Payments for Environmental Services. World Development, 96, 359-374. https://doi.org/10.1016/j.worlddev.2017.03.020

Braun, V., \& Clarke, V. (2006). Using thematic analysis in psychology. Qualitative Research in Psychology, 3(2), 77-101. https://doi.org/10.1191/1478088706QP063OA

Bull, J. W., \& Strange, N. (2018). The global extent of biodiversity offset implementation under no net loss policies. Nature Sustainability, 1(12), 790-798. https://doi.org/10.1038/s41893-018-0176-z

Campbell, L. M., \& Cornwell, M. L. (2008). Human dimensions of bycatch reduction technology: Current assumptions and directions for future research. Endangered Species Research, 5(2-3), 325-334. https://doi.org/10.3354/esr00172 
Carson, R. T., Flores, N. E., \& Meade, N. F. (2001). Contingent Valuation: Controversies and Evidence. Environmental and Resource Economics 2001 19:2, 19(2), 173-210. https://doi.org/10.1023/A:1011128332243

Carson, R. T., \& Hanemann, W. M. (2005). Contingent Valuation. In Handbook of Environmental Economics (Vol. 2, pp. 821-936). Elsevier. https://doi.org/10.1016/S1574-0099(05)02017-6

CBD. (2020). Update of the Zero Draft of the Post-2020 Global Biodiversity Framework. https://www.cbd.int/doc/c/efb0/1 f84/a892b98d2982a829962b6371/wg2020-02-03-en.pdf

Christie, A. P., Amano, T., Martin, P. A., Petrovan, S. O., Shackelford, G. E., Simmons, B. I., Smith, R. K., Williams, D. R., Wordley, C. F. R., \& Sutherland, W. J. (2020). Poor availability of context-specific evidence hampers decision-making in conservation. Biological Conservation, 248, 108666. https://doi.org/10.1016/J.BIOCON.2020.108666

Cinner, J. E. (2018). How behavioral science can help conservation. Science, 362(6417), 889-890. https://doi.org/10.1126/science.aau6028

Cinner, J. E., Barnes, M. L., Gurney, G. G., Lockie, S., \& Rojas, C. (2021). Markets and the crowding out of conservation-relevant behavior. Conservation Biology, 35(3), 816-823. https://doi.org/10.1111/cobi.13606

Cinner, J. E., Daw, T., \& McClanahan, T. R. (2009). Socioeconomic factors that affect artisanal fishers' readiness to exit a declining fishery. Conservation Biology, 23(1), 124-130. https://doi.org/10.1111/j.15231739.2008.01041.x

Cinner, J. E., Folke, C., Daw, T., \& Hicks, C. C. (2011). Responding to change: Using scenarios to understand how socioeconomic factors may influence amplifying or dampening exploitation feedbacks among Tanzanian fishers. Global Environmental Change, 21(1), 7-12. https://doi.org/10.1016/j.gloenvcha.2010.09.001

Collins, C., Bech Letessier, T., Broderick, A., Wijesundara, I., \& Nuno, A. (2020). Using perceptions to examine human responses to blanket bans: The case of the thresher shark landing-ban in Sri Lanka. Marine Policy, September, 104198. https://doi.org/10.1016/j.marpol.2020.104198

Conlisk, J. (1996). Why Bounded Rationality? Journal of Economic Literature, 34(2), 669-700. https://msuweb.montclair.edu/ lebelp/ConliskBdRationalJEL1996.pdf

Díaz, S., Settele, J., Brondízio, E. S., Ngo, H. T., Agard, J., Arneth, A., Balvanera, P., Brauman, K. A., Butchart, S. H. M., Chan, K. M. A., Lucas, A. G., Ichii, K., Liu, J., Subramanian, S. M., Midgley, G. F., Miloslavich, P., Molnár, Z., Obura, D., Pfaff, A., ... Zayas, C. N. (2019). Pervasive human-driven decline of life on Earth 
points to the need for transformative change. In Science (Vol. 366, Issue 6471). American Association for the Advancement of Science. https://doi.org/10.1126/science.aax3100

661

Dulvy, N. K., Pacoureau, N., Rigby, C. L., Pollom, R. A., Jabado, R. W., Ebert, D. A., Finucci, B., Pollock, C. M., Cheok, J., Derrick, D. H., Herman, K. B., Sherman, C. S., VanderWright, W. J., Lawson, J. M., Walls, R. H. L., Carlson, J. K., Charvet, P., Bineesh, K. K., Fernando, D., ... Simpfendorfer, C. A. (2021). Overfishing drives over one-third of all sharks and rays toward a global extinction crisis. Current Biology, 31(21), 47734787.e8. https://doi.org/10.1016/J.CUB.2021.08.062

Engel, S., Pagiola, S., \& Wunder, S. (2008). Designing payments for environmental services in theory and practice: An overview of the issues. Ecological Economics, 65(4), 663-674. https://doi.org/10.1016/j.ecolecon.2008.03.011

Ferraro, P. J., \& Pattanayak, S. K. (2006). Money for Nothing? A Call for Empirical Evaluation of Biodiversity Conservation Investments. PLOS Biology, 4(4), e105. https://doi.org/10.1371/JOURNAL.PBIO.0040105

Ferraro, P. J., \& Simorangkir, R. (2020). Conditional cash transfer to alleviate poverty also reduce deforestation in Indonesia. Science Advances, 6, eaaz1298. https://advances.sciencemag.org/content/6/24/eaaz1298/tab-pdf

Gallagher, A. J., Orbesen, E. S., Hammerschlag, N., \& Serafy, J. E. (2014). Vulnerability of oceanic sharks as pelagic longline bycatch. Global Ecology and Conservation, 1, 50-59. https://doi.org/10.1016/j.gecco.2014.06.003

Gallo-Cajiao, E., Archibald, C., Friedman, R., Steven, R., Fuller, R. A., Game, E. T., Morrison, T. H., \& Ritchie, E. G. (2018). Crowdfunding biodiversity conservation. Conservation Biology, 32(6), 1426-1435. https://doi.org/10.1111/cobi.13144

Gibbons, J. M., Nicholson, E., Milner-Gulland, E. J., \& Jones, J. P. G. (2011). Should payments for biodiversity conservation be based on action or results? Journal of Applied Ecology, 48(5), 1218-1226. https://doi.org/10.1111/J.1365-2664.2011.02022.X

Gneezy, U., Meier, S., \& Rey-Biel, P. (2011). When and Why Incentives (Don't) Work to Modify Behavior. Joumal of Economic Perspectives, 25(4), 191-210. https://doi.org/10.1257/jep.25.4.191

Golden, C. D., Allison, E. H., Cheung, W. W. L., Dey, M. M., Halpern, B. S., McCauley, D. J., Smith, M., Vaitla, B., Zeller, D., \& Myers, S. S. (2016). Nutrition: Fall in fish catch threatens human health. Nature News, 534(7607), 317. https://doi.org/10.1038/534317a 
Grillos, T., Bottazzi, P., Crespo, D., Asquith, N., \& Jones, J. P. G. (2019). In-kind conservation payments crowd in environmental values and increase support for government intervention: A randomized trial in Bolivia. Ecological Economics, 166(January), 106404. https://doi.org/10.1016/j.ecolecon.2019.106404

Grimm, P. (2010). Social Desirability Bias. Wiley International Encyclopedia of Marketing. https://doi.org/10.1002/9781444316568.WIEM02057

Gutiérrez, N. L., Hilborn, R., \& Defeo, O. (2011). Leadership, social capital and incentives promote successful fisheries. Nature, 470(7334), 386-389. https://doi.org/10.1038/nature09689

Hau, Y. C. L., Abercrombie, D., Ho, K. Y. K., \& Shea, K. H. S. (2018). King of Shark Fins: A rapid survey on the availability of Shark-like batoid fins in Hong Kong $S A R$ and Guangzhou, China retail markets. http://www.bloomassociation.org/en/wp-content/uploads/2018/12/King-of-shark-fins-not-quitesharks.pdf

Innes, J., Pascoe, S., Wilcox, C., Jennings, S., \& Paredes, S. (2015). Mitigating undesirable impacts in the marine environment: a review of market-based management measures. Frontiers in Marine Science, 2(OCT), 76. https://doi.org/10.3389/fmars.2015.00076

IUCN. (2021). IUCN Red List of Threatened Species Version 2021-1. https://www.iucnredlist.org/resources/summary-statistics

Jacob, C., van Bochove, J. W., Livingstone, S., White, T., Pilgrim, J., \& Bennun, L. (2020). Marine biodiversity offsets: Pragmatic approaches toward better conservation outcomes. Conservation Letters, 13(3), 1-12. https://doi.org/10.1111/conl.12711

Jaiteh, V., Loneragan, N., \& Warren, C. (2017). The end of shark finning? Impacts of declining catches and fin demand on coastal community livelihoods. Marine Policy, 82(March), 224-233. https://doi.org/10.1016/j.marpol.2017.03.027

Jouffray, J. B., Crona, B., Wassénius, E., Bebbington, J., \& Scholtens, B. (2019). Leverage points in the financial sector for seafood sustainability. Science Advances, 5(10), eaax3324. https://doi.org/10.1126/sciadv.aax3324

Kahneman, D., \& Tversky, A. (1979). Prospect Theory: An Analysis of Decision under Risk. Econometrica, 47(2), 263-292. http://www.jstor.org/stable/1914185\%5Cnhttp://www.jstor.org/\%5Cnhttp://www.jstor.org/action/sho wPublisher?publisherCode=econosoc.\%5Cnhttp://www.jstor.org 
Keane, A., Jones, J. P. G. G., Edwards-Jones, G., \& Milner-Gulland, E. J. (2008). The sleeping policeman: Understanding issues of enforcement and compliance in conservation. Animal Conservation, 11(2), 75-82. https://doi.org/10.1111/j.1469-1795.2008.00170.x

Kotchen, M. J., \& Segerson, K. (2019). On the use of group performance and rights for environmental protection and resource management. Proceedings of the National Academy of Sciences of the United States of America, 116(12), 5285-5292. https://doi.org/10.1073/pnas.1802881115

Kotchen, M. J., \& Segerson, K. (2020). The Use of Group-Level Approaches to Environmental and Natural Resource Policy. Review of Environmental Economics and Policy, 14(2), 173-193. https://doi.org/10.1093/reep/reaa002

Kyne, P. M., Jabado, R. W., Rigby, C. L., Dharmadi, Gore, M. A., Pollock, C. M., Herman, K. B., Cheok, J., Ebert, D. A., Simpfendorfer, C. A., \& Dulvy, N. K. (2020). The thin edge of the wedge: Extremely high extinction risk in wedgefishes and giant guitarfishes. Aquatic Conservation: Marine and Freshwater Ecosystems, 30(7), 13371361. https://doi.org/10.1002/aqc.3331

Leduc, A. O. H. C., \& Hussey, N. E. (2019). Evaluation of pay-for-release conservation incentives for unintentionally caught threatened species. Conservation Biology, 33(4), 953-961. https://doi.org/10.1111/cobi.13300

Lew, D. K. (2015). Willingness to pay for threatened and endangered marine species: a review of the literature and prospects for policy use. Frontiers in Marine Science, O(NOV), 96. https://doi.org/10.3389/FMARS.2015.00096

Lewison, R. L., Crowder, L. B., Read, A. J., \& Freeman, S. A. (2004). Understanding impacts of fisheries bycatch on marine megafauna. 19(11), 598-604. https://www.sciencedirect.com/science/article/pii/S0169534704002642

Liebe, U., Preisendörfer, P., \& Meyerhoff, J. (2011). To Pay or Not to Pay: Competing Theories to Explain Individuals' Willingness to Pay for Public Environmental Goods. Article Environment and Behavior, 43(1), 106130. https://doi.org/10.1177/0013916509346229

Lim, F. K. S., Carrasco, L. R., McHardy, J., \& Edwards, D. P. (2017). Perverse Market Outcomes from Biodiversity Conservation Interventions. Conservation Letters, 10(5), 506-516. https://doi.org/10.1111/conl.12332

Ma, Z., Bauchet, J., Steele, D., Godoy, R., Radel, C., \& Zanotti, L. (2017). Comparison of Direct Transfers for 
Human Capital Development and Environmental Conservation. World Development, 99, 498-517. https://doi.org/10.1016/j.worlddev.2017.05.030

Mahieu, P. A., Riera, P., \& Giergiczny, M. (2012). The influence of cheap talk on willingness-to-pay ranges: Some empirical evidence from a contingent valuation study. Journal of Environmental Planning and Management, 55(6), 753-763. https://doi.org/10.1080/09640568.2011.626524

Mangi, S. C., Dolder, P. J., Catchpole, T. L., Rodmell, D., \& de Rozarieux, N. (2015). Approaches to fully documented fisheries: practical issues and stakeholder perceptions. Fish and Fisheries, 16(3), 426-452. https://doi.org/10.1111/faf.12065

Maron, M., Juffe-Bignoli, D., Krueger, L., Kiesecker, J., Kümpel, N. F., Kate, K. ten, Milner-Gulland, E. J., Arlidge, W. N. S., Booth, H., Bull, J. W., Starkey, M., Ekstrom, J. M., Strassburg, B., Verburg, P. H., \& Watson, J. E. M. (2021). Setting robust biodiversity goals. Conservation Letters, e12816. https://doi.org/10.1111/CONL.12816

Milner-Gulland, E. J., Garcia, S., Arlidge, W., Bull, J. W., Charles, A., Dagorn, L., Fordham, S., Graff Zivin, J., Hall, M. A., Shrader, J., Vestergaard, N., Wilcox, C., \& Squires, D. (2018). Translating the terrestrial mitigation hierarchy to marine megafauna by-catch. Fish and Fisheries, 19(3), 547-561. https://doi.org/10.1111/faf.12273

Mohammed, E. Y. (2012). Payments for coastal and marine ecosystem services: prospects and principles. http://pubs.iied.org/17132IIED

Muradian, R. (2013). Payments for Ecosystem Services as Incentives for Collective Action. Society \& Natural Resources, 26(10), 1155-1169. https://doi.org/10.1080/08941920.2013.820816

Ostrom, E. (1990). Governing the Commons: The Evolution of Institutions for Collective Action. Cambridge University Press.

Ostrom, E. (2000). Collective Action and the Evolution of Social Norms. Journal of Economic Perspectives, 14(3), $137-$ 158. https://doi.org/10.1257/JEP.14.3.137

Oyanedel, R., Gelcich, S., \& Milner-Gulland, E. J. (2020). Motivations for (non-)compliance with conservation rules by small-scale resource users. Conservation Letters, 15(5), e12725. https://doi.org/10.1111/conl.12725

Pascual, U., Phelps, J., Garmendia, E., Brown, K., Corbera, E., Martin, A., Gomez-Baggethun, E., \& Muradian, R. (2014). Social Equity Matters in Payments for Ecosystem Services. BioScience, 64(11), 1027-1036. 
https://doi.org/10.1093/BIOSCI/BIU146

Pimiento, C., Leprieur, F., Silvestro, D., Lefcheck, J. S., Albouy, C., Rasher, D. ., Davis, M., Svenning, J.-C., \& Griffin, J. N. (2020). Functional diversity of marine megafauna in the Anthropocene. Science Advances, 6(eaay7650). https://doi.org/10.1126/sciadv.aay7650

Rigby, C. L., Dulvy, N. K., Barreto, R., Carlson, J., Fernando, D., Fordham, S., Francis, M. P., Herman, K., Jabado, R. W., Liu, K. M., Marshall, A., Pacoureau, N., Romanov, E., Sherley, R. B., \& Winker, H. (2019). Sphyma lewini (Scalloped Hammerhead). He IUCN Red List of Threatened Species 2019. https://www.iucnredlist.org/species/39385/2918526\#habitat-ecology

Selig, E. R., Hole, D. G., Allison, E. H., Arkema, K. K., McKinnon, M. C., Chu, J., de Sherbinin, A., Fisher, B., Glew, L., Holland, M. B., Ingram, J. C., Rao, N. S., Russell, R. B., Srebotnjak, T., Teh, L. C. L., Troëng, S., Turner, W. R., \& Zvoleff, A. (2018). Mapping global human dependence on marine ecosystems. Conservation Letters, e12617. https://doi.org/10.1111/conl.12617

Selig, E. R., Turner, W. R., Troëng, S., Wallace, B. P., \& Halpern, B. S. (2014). Global Priorities for Marine Biodiversity Conservation. PLoS ONE, 9(1), 82898. https://doi.org/10.1371/journal.pone.0082898

Semedi, P., \& Schneider, K. (2021). Fishers' responses to the Danish seiner ban and the history of fisheries governance on the Java north coast. Maritime Studies, 20(1), 43-62. https://doi.org/10.1007/s40152-020$00202-1$

Shumway, N., Watson, J. E. M., Saunders, M. I., \& Maron, M. (2018). The Risks and Opportunities of Translating Terrestrial Biodiversity Offsets to the Marine Realm. BioScience, 68(2), 125-133. https://doi.org/10.1093/biosci/bix150

Simeon, B. M., Fajri, I., Ula, S., Muttaqin, E., Ichsan, M., Dharmadi, \& Damora, A. (2020). Laporan teknis pemantauan hasil tangkapan biu dan pari di Provinsi Aceh (Issue December).

Simeon, B. M., Ula, S., Supadminingsih, F. N., Muhsin, Kohar, A., Fikri, M. A., Agustina, S., Asrial, E., Santoso, D., \& Muttaqin, E. (2020). Evaluasi Status Stok Perikanan Hiu dan Pari di Tanjung Luar Tabun 2017-2019.

Stein, R. W., Mull, C. G., Kuhn, T. S., Aschliman, N. C., Davidson, L. N. K., Joy, J. B., Smith, G. J., Dulvy, N. K., \& Mooers, A. O. (2018). Global priorities for conserving the evolutionary history of sharks, rays and chimaeras. Nature Ecology and Evolution. https://doi.org/10.1038/s41559-017-0448-4

Stevenson, T. C., Tissot, B. N., \& Walsh, W. J. (2013). Socioeconomic consequences of fishing displacement from 
marine protected areas in Hawaii. Biological Conservation, 160, 50-58.

https://doi.org/10.1016/j.biocon.2012.11.031

Sykes, H., Mangubhai, S., \& Manley, M. (2018). Contribution of Marine Conservation Agreements to Biodiversity Protection, Fisheries Management and Sustainable Financing in Fiji. https://fiji.wcs.org/Portals/82/reports/WCS MCA Fiji Report 040518 2.pdf?ver=2018-05-08-231334-113

Travers, H., Clements, T., \& Milner-Gulland, E. J. (2016). Predicting responses to conservation interventions through scenarios: A Cambodian case study. Biological Conservation, 204, 403-410. https://doi.org/10.1016/j.biocon.2016.10.040

Travers, H., Selinske, M., Nuno, A., Serban, A., Mancini, F., Barychka, T., Bush, E., Rasolofoson, R. A., Watson, J. E. M., \& Milner-Gulland, E. J. (2019). A manifesto for predictive conservation. Biological Conservation, 237, 12-18. https://doi.org/10.1016/J.BIOCON.2019.05.059

Travers, H., Walsh, J., Vogt, S., Clements, T., \& Milner-gulland, E. J. (2021). Delivering behavioural change at scale : What conservation can learn from other fields. Biological Conservation, 257(March), 109092. https://doi.org/10.1016/j.biocon.2021.109092

Vianna, G. M. S., Meekan, M. G., Rogers, A. A., Kragt, M. E., Alin, J. M., \& Zimmerhackel, J. S. (2018). Sharkdiving tourism as a financing mechanism for shark conservation strategies in Malaysia. Marine Policy, 94, 220226. https://doi.org/10.1016/J.MARPOL.2018.05.008

Walker, S., \& Townsend, R. (2008). ECONOMIC ANALYSIS OF NEW ZEALAND’S DEEMED VALUE SYSTEM Scott Walker, Ministry of Fisheries. IIFET 2008 Vietnam Proceedings, 1-11.

WCS-IP. (2019). Shark and Ray Fisheries Database (NTB). Data-Ikan.Org.

Williams, D. R., Balmford, A., \& Wilcove, D. S. (2020). The past and future role of conservation science in saving biodiversity. Conservation Letters, 13(4), 1-7. https://doi.org/10.1111/conl.12720

Wosnick, N., Da Costa De Lima Wosiak, C., \& Machado Filho, O. C. (2020). Pay to conserve: what we have achieved in 10 years of compensatory releases of threatened with extinction guitarfishes. Animal Conservation, 1-3. https://doi.org/10.1111/acv.12651

Wu, J. (2016). Shark fin and mobulid ray gill plate trade in mainland China, Hong Kong and Taiwan.

Wunder, S. (2005). Payments for environmental services: Some nuts and bolts. http:/ /www.cifor.cgiar.org

Wunder, S., Engel, S., \& Pagiola, S. (2008). Taking stock: A comparative analysis of payments for environmental 
services programs in developed and developing countries. Ecological Economics, 65(4), 834-852. https://doi.org/10.1016/j.ecolecon.2008.03.010

Wyborn, C., \& Evans, M. C. (2021). Conservation needs to break free from global priority mapping. Nature Ecology and Evolution, 5(10), 1322-1324. https://doi.org/10.1038/s41559-021-01540-x

831 Yin, R. K. (2003). Case study research: design and methods. Sage Publication.

832 Yulianto, I., Booth, H., Ningtias, P., Kartawijaya, T., Santos, J., Sarmintohadi, Kleinertz, S., Campbell, S. J., Palm, Indonesian targeted shark fishery. PLOS ONE, 13(11), e0206437. 